\title{
Improving quality of primary care reduces depression and improves quality of life in adolescents
}

Asarnow JR, Jaycox LH, Duan $\mathrm{N}$, et al. Effectiveness of a quality improvement intervention for adolescent depression in primary care clinics: a randomized controlled trial. JAMA 2005;293:311-19.

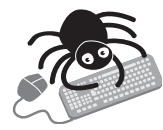

What are the effects of improving quality of primary care in adolescents with depression?

METHODS

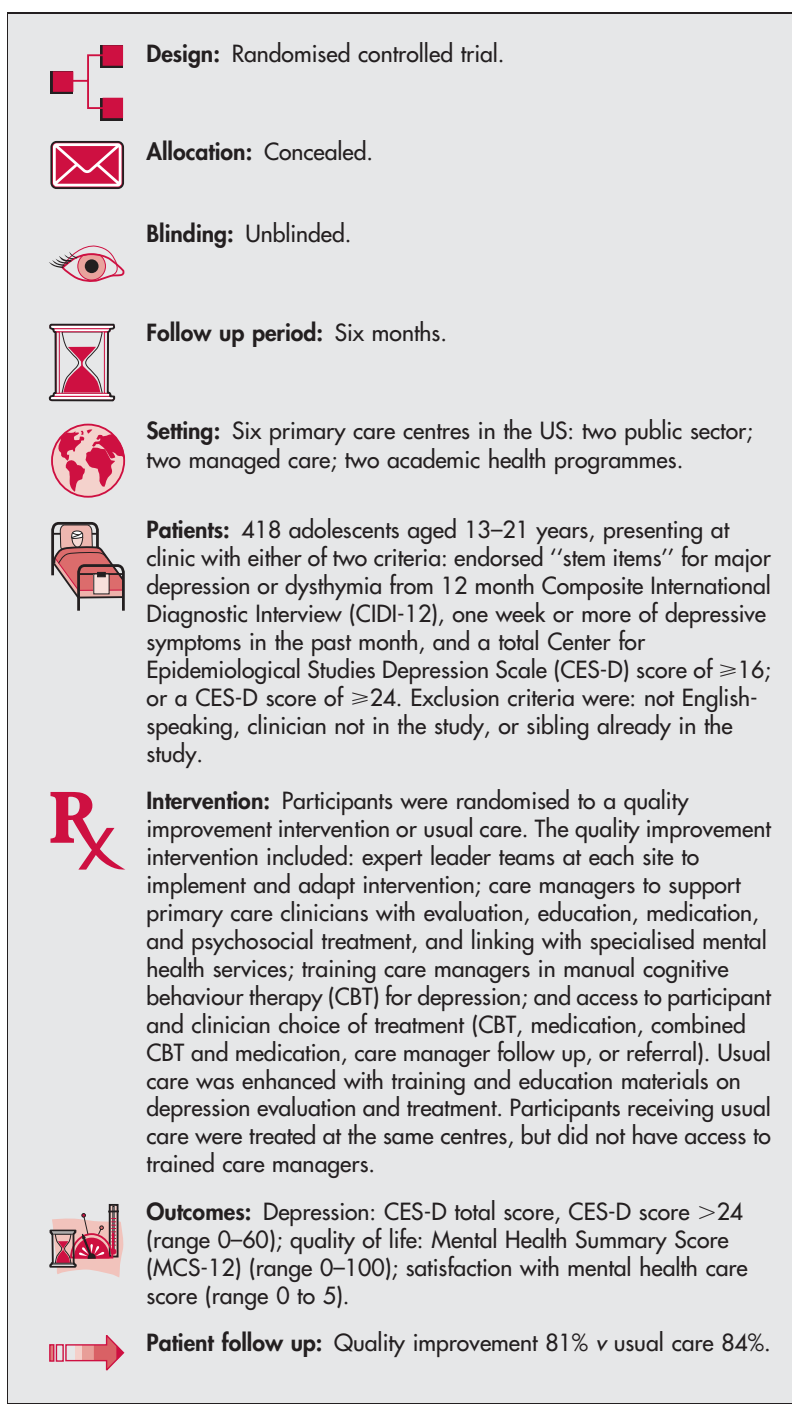
For correspondence: Joan Rosenbaum Asarnow, PhD, UCLA Neuropsychiatric Institute, David Geffen School of Medicine at UCLA, 760 Westwood Plaza, Los Angeles, CA 90024-1759, USA; jasarnow@mednet.ucla.edu

Sources of funding: Agency for Health Care Research and Quality, National Institute of Mental Health.

\section{MAIN RESULTS}

In adolescents with depression, quality improvement intervention reduced depression, and increased mental health quality of life and satisfaction with mental health care compared with usual care (see http://www.ebmentalhealth.com/supplemental for table).

\section{CONCLUSIONS}

Improving quality of primary care by providing extra support to clinicians and increasing access to treatments reduces depression and improves mental health quality of life in adolescents.

\section{Commentary}

U

ntreated depression in teenagers contributes to school and relationship difficulties, family problems, alcohol and substance abuse, and increased suicide rates, and can herald the onset of a lifelong disorder. Primary care can be an effective place to identify depressed teens and initiate treatment. This study demonstrates that it is feasible to introduce into primary care settings a treatment programme for teenagers. The authors developed a chronic illness model' for treating teenage depression, incorporating an innovative and flexible intervention, patient choice of treatment options, a move towards evidence-based care, and-most importantly-organisational changes to support the programme (however, the role of the "expert leaders" responsible for this at each site is not expanded upon). The intervention involved many components: providing information about depression; offering the participants choices of treatments; providing someone for the teen to talk to; the cognitive behaviour therapy itself; and organisational changes. It would have been useful to assess which of these components had the greatest impact on outcomes, and whether any of their effects were synergistic.

One outstanding question remains: how best to identify teenagers in primary care who are depressed. In this study 4034 teens were screened. As 18 more teenagers in the intervention group improved, if the intervention had been available to everyone in the study, by extrapolation only 36 would have improved, or one for every 112 teenagers screened. While evidence regarding the benefits of screening teenagers is lacking, ${ }^{2}$ incorporating two questions concerning mood and anhedonia in a primary care provider's assessment can be as effective as administering a full screening instrument. ${ }^{23}$ Organisational changes in primary care settings that lead to all primary care providers asking these two questions routinely each time they see a teen may prove to be the most efficient way to identify depressed teenagers.

Nick Kates MB.BS, FRCP(C) Professor, Department of Psychiatry and Behavioural Neurosciences, McMaster University, Hamilton, Ontario, Canada

1 Bodenheimer T, Wagner E, Grumbach K. Improving primary care for patients with chronic illness: the chronic care model, part 2. JAMA 2002;288:1909-14.

2 Pignone M, Gaynes B, Rushton J, et al. Screening for depression in adults: a summary of the evidence of the US Preventive Services Task Force. Ann Int Med 2002; 136:765-76.

3 Whooley M, Avins A, Miranda J, et al. Case-finding instruments for depression. Two questions are as good as many. J Gen Intern Med $1997 ; 12: 439-45$ 